\title{
Proximal Fifth Metatarsal Fractures: Anatomy, Classification, Treatment and Complications
}

\author{
Chi Nok Cheung, ${ }^{1}$ and Tun Hing Lui ${ }^{1, *}$ \\ ${ }^{1}$ Department of Orthopedics and Traumatology, North District Hospital, Hong Kong SAR, China \\ "Corresponding author: Tun Hing Lui, Department of Orthopedics and Traumatology, North District Hospital, 9 Po Kin Road, Sheung Shui, NT, Hong Kong SAR, China. Tel: \\ +852-26837588, Fax: +852-26837576, E-mail: luithderek@yahoo.co.uk
}

Received 2015 September 20; Revised 2016 March 31; Accepted 2016 May 22.

\begin{abstract}
Context: Fractures of proximal fifth metatarsal are one of the most common fractures of the foot.

Evidence Acquisition: A search of PubMed for studies on proximal fifth metatarsal fracture and Jones fracture focusing on the classification and management was performed. The reference list of the retrieved articles was searched for additional related studies. Results: The vascular supply and soft tissue anatomy of the fifth metatarsal explains the increased risk of delayed union and nonunion in fractures at the metaphyseal-diaphyseal junction. Lawrence and Botte classify proximal fifth metatarsal fractures according to their location: tuberosity avulsion fractures (zone 1), fractures at metaphyseal-diaphyseal junction extending into the fourthfifth intermetatarsal joint (zone 2) and proximal diaphyseal fractures (zone 3). Zone 1 fractures are treated conservatively with functional immobilization and early mobilization with excellent outcome. For zone 2 and zone 3 fractures, acute forms can be treated conservatively but with a risk of delayed union time and time for return to function. Therefore, early surgical fixation with intramedullary screw is advised in athletic individuals. For cases presented with signs of delayed union and non-union, surgical treatment with or without bone grafting is recommended. Complications of these fractures and their management are discussed in this report.

Conclusions: Lawrence and Botte's classification of proximal fifth metatarsal fractures is recommended by experts, due to its implication on prognosis and treatment strategy. Zone 1 fractures should be treated conservatively due to their excellent healing potential. Early operative treatment is advised for zone 2 and zone 3 fractures, especially in the athletic group. Complications of delayed union, non-union and refractures should be treated by revision fixation and bone grafting.
\end{abstract}

Keywords: Metatarsal Bones, Fractures, Bone, Evidence-Based Medicine, Classification, Anatomy, Fracture Fixation

\section{Context}

Fractures of the fifth metatarsal are among the most common fractures of the foot (1). Many of these fractures are located proximally (2). The fracture of the proximal fifth metatarsal was first described by Sir Robert Jones in 1902 (3). Thereafter, different classification systems and management strategies were described in the literature. From Joseffson's series (4), proximal fifth metatarsal fractures usually occur during the second to sixth decades of life. Dameron (5) and Ekrol (6) observed that there is a male predominance in younger patients while a female predominance exists in older patients. These fractures are commonly a result of sport activities but can also happen in non-athletics (7-9).

The aim of this article was to review the pathoanatomy of proximal fifth metatarsal fracture, its classifications, treatment strategies, its complications and the management of the complications based on current evidence in the literature.

\section{Evidence Acquisition}

A review of the literature using PubMed, as the search engine for English articles on proximal fifth metatarsal fracture and Jones fracture, focusing on the classification and management was performed in July 2015. The following search terms were used: metatarsal fracture, fifth metatarsal fracture, Jones fracture, classification, management, operative treatment, delayed union and non-union. The reference list of the retrieved articles was subsequently searched for additional related studies.

\section{Results}

\subsection{Anatomy}

Understanding the anatomy of the proximal part of the fifth metatarsal is important because it explains the injury mechanism and the healing potential of different types of fifth metatarsal fractures, which affect the proper choice of management. The proximal fifth metatarsal includes, fractures from the proximal to the distal area, the 
tuberosity, the metaphysis and the proximal diaphysis. It articulates with the cuboid bone proximally and the base of the fourth metatarsal laterally.

\subsubsection{Soft Tissue Attachment}

A cadaveric study by DeVries (10) showed that the lateral band of the plantar fascia attaches to the plantarlateral aspect of the tuberosity, while the peroneus brevis tendon attaches to the dorsolateral aspect of the tuberosity and the peroneus tertius attaches to the dorsal metaphysis. These soft tissue attachments explain the injury mechanism and will be discussed later in this article.

\subsubsection{Inferior Healing Potential at Metaphysis-Diaphysis Junc- tion}

The blood supply to the fifth metatarsal metaphysis is by a network of arterioles entering the non-articulating surface of the tuberosity. The blood supply to the diaphysis is by the nutrient artery entering through the middle of the diaphysis, which gives longitudinal branches proximally and distally. This gives rise to a watershed area at the metaphysis-diaphysis junction, which accounts for the higher risk of delayed union and non-union of fractures in this region (11).

There are strong ligaments between the base of the fifth metatarsal and the cuboid and base of the forth metatarsal, which make this part of the fifth metatarsal relatively fixed $(5,12,13)$. On the other hand, the diaphysis of the fifth metatarsal is relatively mobile. This difference in stability, also makes the metaphyseal-diaphyseal junction fractures biochemically more susceptible to delayed union and non-union (8).

\subsection{Classifications}

Fracture of the proximal fifth metatarsal was first described by Sir Robert Jones in 1902. Thereafter, different classification systems for the proximal fifth metatarsal fractures have been described. The term 'Jones fracture' is used inconstantly; some authors define it as a fracture at the metaphyseal-diaphyseal junction while others define it as a fracture at the proximal diaphysis. Therefore, using proper classification rather than the term 'Jones fracture' is recommended in describing proximal fifth metatarsal fractures.

\subsubsection{Lawrence and Botte's Classification}

The most commonly used classification was described by Lawrence and Botte in 1993 (14). It distinguishes three types of proximal fifth metatarsal fractures based on the mechanism of injury, location, treatment options and prognosis. Zone 1 fractures refer to avulsion fractures of the tuberosity with or without involvement of the tarsometatarsal articulation. This is caused by forces by the peroneus brevis tendon or the lateral band of the plantar fascia during foot inversion. Zone 2 fractures refer to fractures at the metaphysis-diaphysis junction, which extend into the fourth-fifth intermetatarsal facet. This is caused by forced forefoot adduction with the hindfoot in plantar flexion. Zone 3 fractures refer to proximal diaphyseal fractures, distal to the fourth and fifth metatarsal base articulation. This is caused by acute excessive bearing of the region or chronic overloading as in stress fractures (Figure 1).

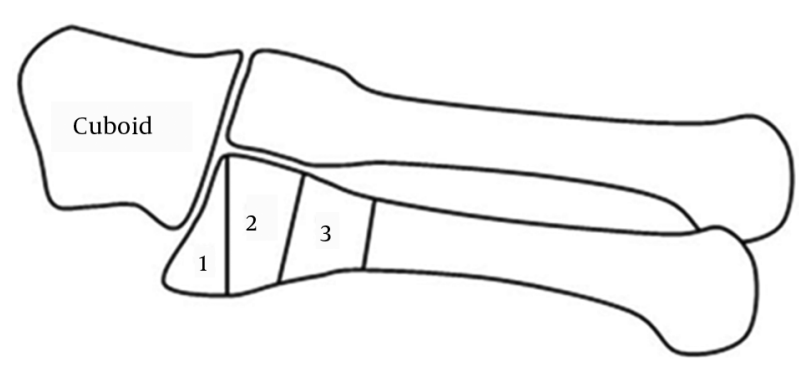

Figure 1. Lawrence and Botte's Classification of Proximal Fifth Metatarsal Fractures (Zone 1, 2 and 3)

Zone 1 fractures are the most common and usually lead to good outcomes with conservative treatment. Zone 2 and 3 fractures are prone to delayed union and even nonunion, as explained previously, therefore require specific treatment strategies.

\subsubsection{Torg's Classification}

Torg (15) developed further classification for fractures at zone 2 and 3 for formulating a suitable treatment plan. Type I (acute) is a fracture with a narrow fracture line and no intramedullary sclerosis. Type II (delayed union) is a fracture with wide fracture line and intramedullary sclerosis. Type III (non-union) is a fracture with complete obliteration of the medullary canal by the sclerotic bone.

\subsubsection{Isolated Proximal Fifth Metatarsal Fractures Versus. Lis-} franc Injury

It is also important to assess clinically and radiologically for any evidence of Lisfranc injury over the medial column, because management of isolated proximal fifth metatarsal fracture and those associated with Lisfranc injury are completely different. In cases with Lisfranc injuries, management of compartment syndrome if any and early anatomical reduction and fixation of the Lisfranc joint and the other tarsometatarsal articulations are required. Delay in treatment of the Lisfranc component is associated with poor outcome including development of post-traumatic arthritis (Figure 2) (16). 

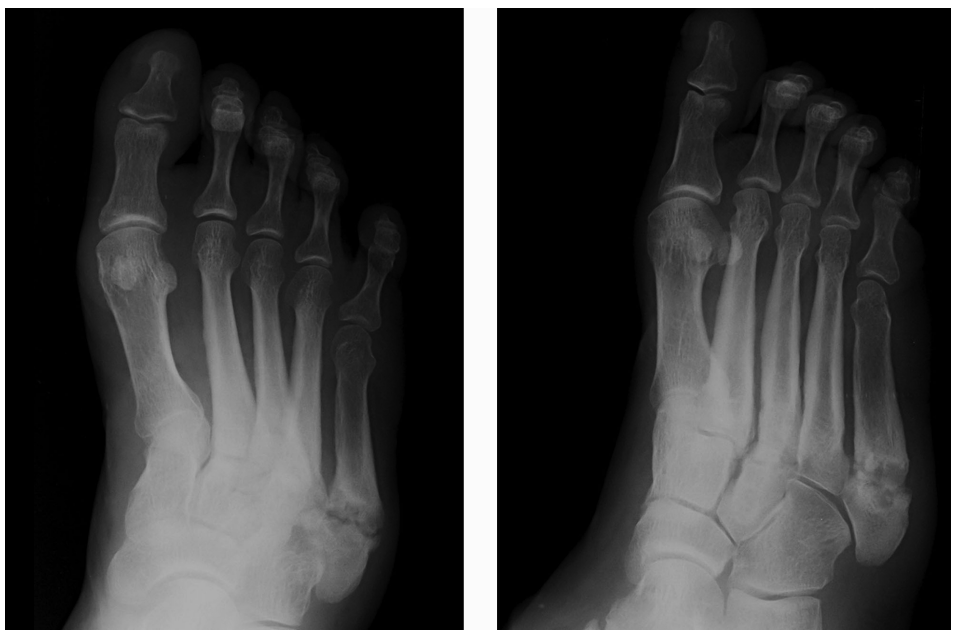

Figure 2. A case of Proximal Fifth Metatarsal Fracture With Missed Lisfranc Injury That Resulted In Nonunion of the Fracture and Degeneration of the Lisfranc Joint

\subsection{Treatment}

\subsubsection{Zone 1 Fractures}

There is no controversy that non-displaced tuberosity avulsion fractures should be treated conservatively in view of their excellent healing potential. A meta-analysis of 187 tuberosity avulsion fractures from four studies in 2011 showed that there was no significant difference in union and refracture rates between different conservative treatment modalities (17). However, studies have shown that functional treatments with early weight bearing provide better functional outcome and earlier return to work than treatment by short leg cast with non-weight bearing walking (18-21). Therefore, functional treatments with orthopedic shoe, Jones bandage dressing or elastic bandage dressing are recommended.

Some authors suggested that fracture displacement of more than $2 \mathrm{~cm}$ and involvement of more than 30\% of the cuboid-metatarsal articulation are indications for operative treatment of tuberosity avulsions (8). However, another study showed that functional treatment in this group of fractures gives good results compared to nondisplaced and extra-articular fractures (15) (Figure 3).

\subsubsection{Zone 2 and Zone 3 Fractures}

Josefsson demonstrated over 95\% union rate, satisfactory long-term result and satisfactory functional outcome with non-operative treatment by short leg cast immobilization (4). However, the main disadvantage was delayed union time and longer time to return to function. Eight out of the 44 patients in his study required secondary fixation surgery due to delayed union.
Torg suggested a treatment strategy according to his subgroups for the fractures at zone 2 and 3 (22). Type I fractures can be treated conservatively with non-weight bearing in a short leg cast for a period of 3 to 12 weeks (Figure 4). Type II fractures can be treated conservatively or operatively depending on the functional demand since most of these fractures heal eventually with conservative treatment but early surgical treatment may reduce the time of union and the time of immobilization. Type III factures should be managed operatively.

Mologne performed the only randomized controlled study comparing the outcome of early intramedullary screw fixation versus casting for Type I fractures (23). Among the recruited 37 patients (18 patients with casting and 19 patients with screw fixation), he observed that nonoperative treatment causes a relatively high rate of treatment failure (44\%) and doubles the time to clinical union and return to sports.

Rosenberg shared a similar opinion in his review paper on treatment for zone 2 and 3 fractures (24). He recommends conservative treatment with non-weight bearing in a short leg cast for six to eight weeks for acute fractures in the non-athletic group and surgical fixation in athletic patients for earlier union and return to function. For delay union and non-union cases, he recommends surgical treatment with or without bone grafting.

\subsubsection{Operative Techniques}

Different operation techniques were described in the literature including intramedullary screw, tension band wiring, differential pitch screw and percutaneous bicortical screw. Fixation with intramedullary compression 
Figure 3. A Case of Lawrence and Botte Zone 1 Fracture That Was Treated Conservatively With Rocker Boot
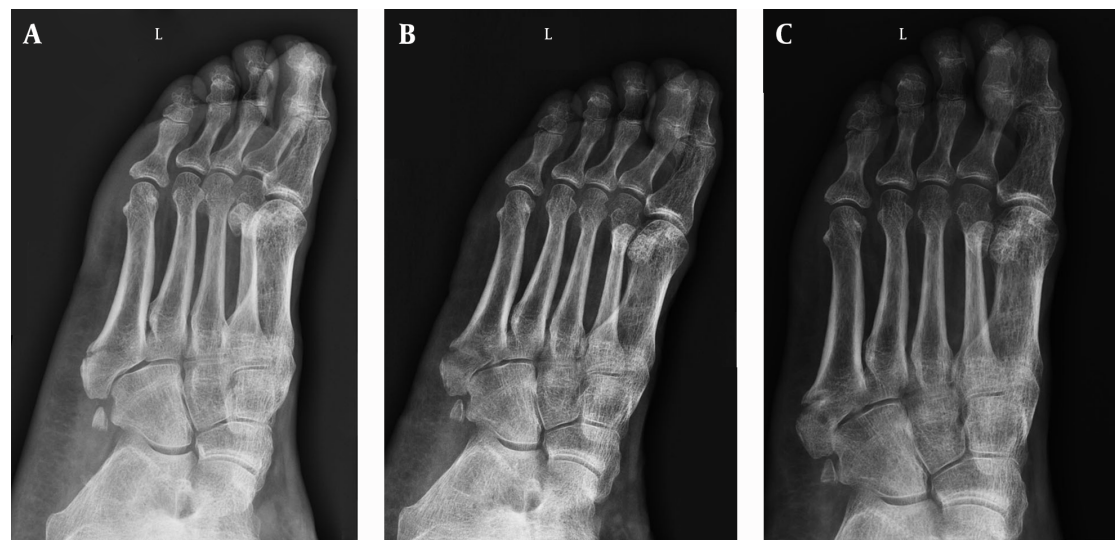

A, injury film showing non-displaced fracture. B, radiograph taken six weeks after the injury, showing fracture displacement. C, radiograph taken nine months after the injury showing that the fracture had healed.

Figure 4. A Case of Lawrence and Botte Zone 3 Fracture Treated Conservatively With a Cast
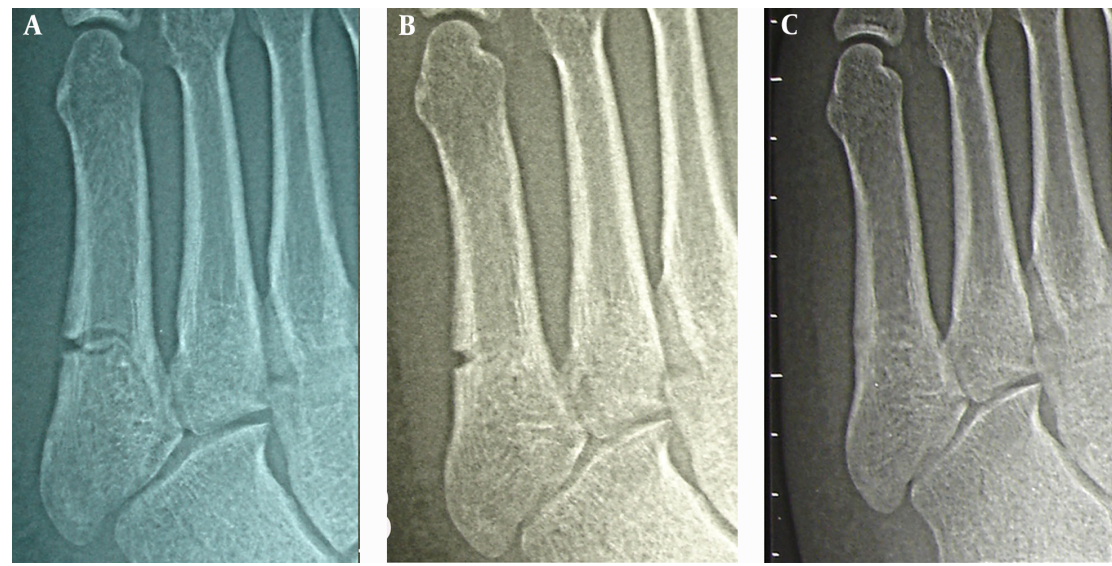

A, injury film. B, radiograph taken nine weeks after the injury showed that the fracture healed with residual lateral cortical notch. The notch is a common radiographic appearance after the fracture heals. It takes a long time to disappear. C, radiograph taken 15 months after the injury, showed the notch disappeared.

screw with or without bone grafts is the most commonly reported technique (8). Reaming of the medullary canal before screw insertion is advised to ensure tight fit of the screw to the endosteum. A partially-threaded screw is used and all the screw threads must pass though the fracture line in order to achieve fracture compression. A cadaveric study by Shah showed that there is no correlation between the size of the screws and biomechanical advantage (25). A clinical analysis by Larson also showed that the screw diameter is not predictive of refracture or non-union (26). A larger screw may provide a better pull out strength but may also increase the risk of diaphyseal fracture during insertion. Porter reported a 100\% union rate, high satisfaction and no refractures in a group of high physi- cal demand athletic patients using $4.5 \mathrm{~mm}$ cannulated intramedullary screw fixation (27). Similar excellent result was also demonstrated in a more recent study by Massada in 2012 (28).

Tension band wiring is an alternative operative treatment for proximal fifth metatarsal fractures. A recent study modified the tension band wiring technique with the use of two cortical screws and gave comparable outcomes to those of intramedullary screw fixation while the risks of sural nerve injury and neuralgia is reduced compared with the conventional tension band technique (12). Variable pitch tapered screw fixation and percutaneous bicortical screw fixation have been previously described but the clinical evidence at present is still limited $(29,30)$. 


\subsubsection{Post-Operative Rehabilitation}

Post-operative rehabilitation $(7,23,30)$ usually consists of immobilization with a short leg cast or plaster splint for one to two weeks, and then replacement with a walking boot. Patients are allowed to start progressive weight bearing from week four onwards. By six to eight weeks post-operatively, full weight-bearing walking is allowed and normal activities can be resumed. Some authors suggest extension of the initial period of cast immobilization and non-weight bearing to six weeks in case of stress fractures of the proximal diaphysis (12). Return to sports should only be allowed when there is radiological evidence of union and the patient is clinically asymptomatic (26). The rehabilitation plan must be accepted by the patient pre-operatively since pre-mature return to vigorous physical activity is believed to cause delayed union and refracture, especially in athletic patients (31).

\subsubsection{Contraindications of Surgical Treatment}

There is no evidence on specific contraindications of surgical treatment for proximal fifth metatarsal fractures. In general, surgical treatment is contraindicated in feet with vascular comprise, neuropathy or local infection. Diabetes mellitus itself is not an absolute contraindication providing that the vascular supply and protective sensation of the long extremities are still intact (32).

\subsection{Complications}

\subsubsection{General Complications}

Complications of proximal fifth metatarsal fractures include delay union, non-union and refracture (31). A low non-union rate of $0.5 \%-1 \%$ was reported in zone 1 fractures treated conservatively $(20,33)$. In contrast, non-union rate of zone 2 and zone 3 fractures treated conservatively is as high as 25 - 28\% $(23,33,34)$. Kavanaugh (35) also reported a high delayed union rate of $66.7 \%$ and a high refracture rate of $61.1 \%$ for zone 2 and zone 3 fractures.

For tuberosity, avulsion fractures failed conservative treatment; screw fixation with or without bone graft and excision of the extra-articular avulsion fragment are the treatment options (36). Lui described the technique of endoscopic assisted screw fixation and bone grafting, which avoids extensive soft tissue dissection, allows assessment of fifth metatarsal cuboid articulation and guides the desired position of screw fixation (37).

For fractures at zone 2 and 3, non-union and refracture could be treated with medullary curettage and inlay grafting or intramedullary screw fixation $(38,39)$. In case of revision in previous screw fixation, a larger diameter screw and re-reaming of the medullary canal is required (40). A case series by Sarimo (41) showed that tension-band wiring as a secondary procedure for delayed union or nonunion with prior unsuccessful conservative treatment or intramedullary screw fixation also give promising results. In his series, there was no delayed union, non-union or refracture upon follow-up.

Electrical stimulation with pulsed electromagnetic fields showed promising early results for proximal fifth metatarsal fractures, especially in cases of delayed union and non-union $(42,43)$. More studies on the effectiveness of this adjunctive are required.

\subsubsection{Operation Related Complications}

Other specific possible complications of surgical fixation include wound infection, rupture of peroneus brevis tendon, peroneal nerve irritation, sural nerve injury, impingement by prominent screw head, screw missing the medullary canal, iatrogenic fracture of the metatarsal bone and metatarsalgia $(7,44,45)$. Wound infection and tendon or nerve injury can be avoided by careful soft tissue handling and using a low profile implant. Impingement by screw head can be prevented by adequate countersink of the cortex before screw insertion and can be managed by wearing more spacious shoes (7). Screws missing the medullary canal and iatrogenic fracture can be avoided by a proper surgical technique and careful choice of suitable implant $(35,40)$. One of the causes of post-operative metatarsalgia is fibrosis of the joints and tendons around the operative site. Lui reported a case of post-operative lateral foot pain successfully treated by arthroscopic arthrolysis and endoscopic tenolysis (46).

\section{Conclusions}

Proximal fifth metatarsal fractures are common. Knowing the anatomy is important for understanding the mechanism and prognosis of different types of fractures. The classification by Lawrence and Botte and that by Torg help to formulate appropriate treatment strategies accordingly. Fifth metatarsal fracture associated with Lisfranc injury must be distinguished from isolated proximal fifth metatarsal fracture because their prognosis and management are different.

Avulsion tuberosity fractures (zone 1) should be initially managed conservatively with functional treatment and early weight bearing since the union rate and functional outcome are good.

Zone 2 and zone 3 fractures are more prone to delayed union, non-union and refracture. For acute cases, conservative treatment with cast immobilization and nonweight bearing can be considered in the non-athletic group. While in the athletic group, early surgical fixation with intramedullary screw is advised for shorter union 
time and time to return to sports. Tension band wiring, variable pitch tapered screw fixation and percutaneous bicortical screw fixation are other described surgical techniques. For cases of delayed union and non-union, surgical treatment with or without bone grafting is recommended. Post-operatively, the rehabilitation plan should be agreed and strictly followed by patients.

Complications of proximal fifth metatarsal fractures include delay union, non-union, refracture, soft tissue complications and implant impingement. Some of these could be prevented by careful soft tissue handling, proper surgical technique and suitable choice of implant. Symptomatic delayed union, non-union and refracture should be treated with revision intramedullary screw fixation and bone grafting. Arthroscopic or endoscopic assisted technique may provide a minimally invasive approach of the operative treatment.

\section{Footnotes}

Authors' Contribution: Chi Nok Cheung prepared the manuscript. Tun Hing Lui supervised the work of Chi Nok Cheung.

Financial Disclosure: There was no financial and personal relationships with other people or organizations that could inappropriately influence (bias) the preparation of this manuscript.

Funding/Support: No funding or support was received from any source for preparation of this manuscript.

\section{References}

1. Metcalfe SA. Non-united fifth metatarsal metaphyseal fractures. The Foot. 2001;11(2):99-102.

2. Petrisor BA, Ekrol I, Court-Brown C. The epidemiology of metatarsal fractures. Foot Ankle Int. 2006;27(3):172-4. [PubMed: 16539897].

3. Jones R. I. Fracture of the Base of the Fifth Metatarsal Bone by Indirect Violence. Ann Surg. 1902;35(6):697-700 2. [PubMed: 17861128].

4. Josefsson PO, Karlsson M, Redlund-Johnell I, Wendeberg B. Closed treatment of Jones fracture. Good results in 40 cases after 11-26 years. Acta Orthop Scand. 1994;65(5):545-7. [PubMed: 7801760].

5. Dameron TB. Fractures of the Proximal Fifth Metatarsal: Selecting the Best Treatment Option. J Am Acad Orthop Surg. 1995;3(2):110-4. [PubMed: 10790659].

6. Ekrol I, Court-Brown CM. Fractures of the base of the 5th metatarsal. The Foot. 2004;14(2):96-8.

7. DeLee JC, Evans JP, Julian J. Stress fracture of the fifth metatarsal. Am J Sports Med. 1983;11(5):349-53. [PubMed: 6638251].

8. Zwitser EW, Breederveld RS. Fractures of the fifth metatarsal; diagnosis and treatment. Injury. 2010;41(6):555-62. [PubMed: 19570536].

9. Nielsen TR, Lindblad BE, Faun P. Long-term results after fracture of the fifth metatarsal. JFAS. 1998;4(4):227-32.

10. DeVries JG, Taefi E, Bussewitz BW, Hyer CF, Lee TH. The fifth metatarsal base: anatomic evaluation regarding fracture mechanism and treatment algorithms. J Foot Ankle Surg. 2015;54(1):94-8. [PubMed: 25441854].
11. Smith JW, Arnoczky SP, Hersh A. The intraosseous blood supply of the fifth metatarsal: implications for proximal fracture healing. Foot Ankle. 1992;13(3):143-52. [PubMed:1601342].

12. Lee KT, Park YU, Young KW, Kim JS, Kim JB. Surgical results of 5th metatarsal stress fracture using modified tension band wiring. Knee Surg Sports Traumatol Arthrosc. 2011;19(5):853-7. [PubMed: 21290105].

13. Landorf KB. Fifth metatarsal fractures are not all the same: proximal diaphyseal fractures are prone to delayed healing. The Foot 1998;8(1):38-45.

14. Lawrence SJ, Botte MJ. Jones' fractures and related fractures of the proximal fifth metatarsal. Foot Ankle. 1993;14(6):358-65. [PubMed: 8406253].

15. Torg JS. Fractures of the base of the fifth metatarsal distal to the tuberosity. Orthopedics. 1990;13(7):731-7. [PubMed: 2197611].

16. Eleftheriou KI, Rosenfeld PF, Calder JD. Lisfranc injuries: an update. Knee Surg Sports Traumatol Arthrosc. 2013;21(6):1434-46. [PubMed: 23563815].

17. Smith TO, Clark A, Hing CB. Interventions for treating proximal fifth metatarsal fractures in adults: a meta-analysis of the current evidence-base. Foot Ankle Surg. 2011;17(4):300-7. [PubMed: 22017907].

18. Vorlat P, Achtergael W, Haentjens P. Predictors of outcome of nondisplaced fractures of the base of the fifth metatarsal. Int Orthop 2007;31(1):5-10. [PubMed: 16721621].

19. Egol K, Walsh M, Rosenblatt K, Capla E, Koval KJ. Avulsion fractures of the fifth metatarsal base: a prospective outcome study. Foot Ankle Int. 2007;28(5):581-3. [PubMed: 17559765]

20. Wiener BD, Linder JF, Giattini JF. Treatment of fractures of the fifth metatarsal: a prospective study. Foot Ankle Int. 1997;18(5):267-9. [PubMed: 9167925].

21. Gray AC, Rooney BP, Ingram R. A prospective comparison of two treatment options for tuberosity fractures of the proximal fifth metatarsal. Foot (Edinb). 2008;18(3):156-8. [PubMed: 20307430].

22. Torg JS, Balduini FC, Zelko RR, Pavlov H, Peff TC, Das M. Fractures of the base of the fifth metatarsal distal to the tuberosity. Classification and guidelines for non-surgical and surgical management. J Bone Joint Surg Am. 1984;66(2):209-14. [PubMed: 6693447].

23. Mologne TS, Lundeen JM, Clapper MF, O'Brien TJ. Early screw fixation versus casting in the treatment of acute Jones fractures. Am J Sports Med. 2005;33(7):970-5. [PubMed:15888715].

24. Rosenberg GA, Sferra JJ. Treatment strategies for acute fractures and nonunions of the proximal fifth metatarsal. J Am Acad Orthop Surg. 2000;8(5):332-8. [PubMed: 11029561].

25. Shah SN, Knoblich GO, Lindsey DP, Kreshak J, Yerby SA, Chou LB. Intramedullary screw fixation of proximal fifth metatarsal fractures: a biomechanical study. Foot Ankle Int. 2001;22(7):581-4. [PubMed: 11503984].

26. Larson CM, Almekinders LC, Taft TN, Garrett WE. Intramedullary screw fixation of Jones fractures. Analysis of failure. Am J Sports Med. 2002;30(1):55-60. [PubMed: 11798997].

27. Porter DA, Duncan M, Meyer SJ. Fifth metatarsal Jones fracture fixation with a $4.5-\mathrm{mm}$ cannulated stainless steel screw in the competitive and recreational athlete: a clinical and radiographic evaluation. Am J Sports Med. 2005;33(5):726-33. [PubMed:15722272].

28. Massada MM, Pereira MA, de Sousa RJ, Costa PG, Massada JL. Intramedullary screw fixation of proximal fifth metatarsal fractures in athletes. Acta Ortop Bras. 2012;20(5):262-5. [PubMed: 24453614].

29. Orr JD, Glisson RR, Nunley JA. Jones fracture fixation: a biomechanical comparison of partially threaded screws versus tapered variable pitch screws. Am J Sports Med. 2012;40(3):691-8. [PubMed: 22227846].

30. Mahajan V, Chung HW, Suh JS. Fractures of the proximal fifth metatarsal: percutaneous bicortical fixation. Clin Orthop Surg. 2011;3(2):140-6. [PubMed: 21629475].

31. Glasgow MT, Naranja RJ, Glasgow SG, Torg JS. Analysis of failed surgical management of fractures of the base of the fifth metatarsal distal to the tuberosity: the Jones fracture. Foot Ankle Int. 1996;17(8):449-57. [PubMed: 8863022]. 
32. Yue JJ, Marcus RE. The role of internal fixation in the treatment of Jones fractures in diabetics. Foot Ankle Int. 1996;17(9):559-62. [PubMed: 8886784].

33. Dameron TB. Fractures and anatomical variations of the proximal portion of the fifth metatarsal. J Bone Joint Surg Am. 1975;57(6):788-92. [PubMed: 1099103].

34. lapper MF, O'Brien TJ, Lyons PM. Fractures of the fifth metatarsal. Analysis of a fracture registry. Clin Orthop Relat Res. 1995(315):238-41. [PubMed: 7634674].

35. Kavanaugh JH, Brower TD, Mann RV. The Jones fracture revisited. J Bone Joint Surg Am. 1978;60(6):776-82. [PubMed: 701310].

36. Ritchie JD, Shaver JC, Anderson RB, Lawrence SJ, Mair SD. Excision of symptomatic nonunions of proximal fifth metatarsal avulsion fractures in elite athletes. Am J Sports Med. 2011;39(11):2466-9. [PubMed: 21841068].

37. Lui TH. Endoscopic bone grafting for management of nonunion of the tuberosity avulsion fracture of the fifth metatarsal. Arch Orthop Trauma Surg. 2008;128(11):1305-7. [PubMed: 18175130].

38. Rettig AC, Shelbourne KD, Wilckens J. The surgical treatment of symptomatic nonunions of the proximal (metaphyseal) fifth metatarsal in athletes. Am J Sports Med. 1992;20(1):50-4. [PubMed: 1554074].

39. Hunt KJ, Anderson RB. Treatment of Jones fracture nonunions and refractures in the elite athlete: outcomes of intramedullary screw fixation with bone grafting. Am J Sports Med. 2011;39(9):1948-54. [PubMed: 21632977].
40. Wright RW, Fischer DA, Shively RA, Heidt RJ, Nuber GW. Refracture of proximal fifth metatarsal (Jones) fracture after intramedullary screw fixation in athletes. Am JSports Med. 2000;28(5):732-6. [PubMed: 11032233].

41. Sarimo J, Rantanen J, Orava S, Alanen J. Tension-band wiring for fractures of the fifth metatarsal located in the junction of the proximal metaphysis and diaphysis. Am J Sports Med. 2006;34(3):476-80. [PubMed: 16303878].

42. Sharrard WJ, Sutcliffe ML, Robson MJ, Maceachern AG. The treatment of fibrous non-union of fractures by pulsing electromagnetic stimulation. J Bone Joint Surg Br. 1982;64(2):189-93. [PubMed: 6978339].

43. Holmes GB. Treatment of delayed unions and nonunions of the proximal fifth metatarsal with pulsed electromagnetic fields. Foot Ankle Int. 1994;15(10):552-6. [PubMed: 7834063].

44. Donatto KC. Operative treatment for fifthmetatarsal base fractures. Oper Tec in Sport Med. 1999;7(1):14-9.

45. Donley BG, McCollum MJ, Murphy GA, Richardson EG. Risk of sural nerve injury with intramedullary screw fixation of fifth metatarsal fractures: a cadaver study. Foot Ankle Int. 1999;20(3):182-4. [PubMed: 10195297].

46. Lui TH. Lateral foot pain following open reduction and internal fixation of the fracture of the fifth metatarsal tubercle: treated by arthroscopic arthrolysis and endoscopic tenolysis. BMJ Case Rep. 2014;2014 [PubMed: 24744074]. 